\title{
Anti-Toxoplasma Activities of Zea Mays and Eryngium Caucasicum Extracts, In Vitro and In Vivo
}

\author{
Ehsan Ahmadpour' ${ }^{1}$ Mohammad Ali Ebrahimzadeh ${ }^{4}$, Mehdi Sharif 2,5, Sara Edalatian ${ }^{2,3}$, \\ Shahabeddin Sarvi ${ }^{2,3}$, Mahbobeh Montazeri ${ }^{2,6}$, Saeed Mehrzadi ${ }^{7}$, Mohammad Akbari $^{2}$, \\ Mohammad Taghi Rahimi ${ }^{8}$, Ahmad Daryani ${ }^{2,3 *}$
}

\footnotetext{
${ }^{1}$ Infectious and Tropical Diseases Research Center, Tabriz University of Medical Sciences, Tabriz, Iran

${ }^{2}$ Toxoplasmosis Research Center, Mazandaran University of Medical Sciences, Sari, Iran

${ }^{3}$ Parasitology and Mycology Department, Sari Medical School, Mazandaran University of Medical Sciences, Sari, Iran

${ }^{4}$ Pharmaceutical Sciences Research Center, School of Pharmacy, Mazandaran University of Medical Sciences, Sari, Iran

${ }^{5}$ Department of Parasitology, School of Medicine, Sari Branch, Islamic AZAD University, Sari, Iran

${ }^{6}$ Student Research Committee, Mazandaran University of Medical Sciences, Sari, Iran

${ }^{7}$ Razi Drug Research Center, Iran University of Medical Sciences, Tehran, Iran 8School of Medicine, Shahroud University of Medical Sciences,

Shahroud, Iran
}

\section{Key Words}

Toxoplasma gondii, Zea mays, Eryngium caucasicum, extracts, In vitro, In vivo

\begin{abstract}
Objectives: Toxoplasmosis is a worldwide health problem that caused by intracellular apicomplexan parasite, Toxoplasma gondii (T. gondii). Considering that the available drugs for toxoplasmosis have serious host toxicity, the aim of the current study was to survey the in vitro and in vivo anti-Toxoplasma activity of Zea mays (Z. mays) and Eryngium caucasicum (E. caucasicum) extracts.
\end{abstract}

Methods: Four concentrations (5, 10, 25, and $50 \mathrm{mg} \mathrm{mL}$ $\left.{ }^{1}\right)$ of Z. mays and E. caucasicum methanolic extracts for $30,60,120$, and 180 min were incubated with infected macrophages and then the viability of $\mathrm{RH}$ strain of $\mathrm{T}$. gondii tachyzoites was evaluated by trypan blue staining method. Also, we evaluated the survival rate of acutely infected mice with the extracts (100 and $200 \mathrm{mg} \mathrm{kg}^{-1}$ day ${ }^{1}$ ) intraperitoneally for 5 days after infection with $2 \times 104$

Received: Jan 15, 2018 Reviewed: Jan 24, 2019 Accepted: Sep 03, 2019 tachyzoites of T. gondii.

Results: The anti-Toxoplasma effect of the methanolic extracts were extremely significant compared to the negative control group in all exposure times $(\mathrm{P}<0.05)$. The Z. mays (10, 25 and $50 \mathrm{mg} \mathrm{mL}^{-1}$ ) killed $100 \%$ of the parasites after 180 and 120 min exposure, respectively. Also, high toxoplasmacidal activity was observed with E. caucasicum extract. Furthermore, treatment of experimentally infected mice with the $\mathrm{Z}$. mays $(100,200$ $\mathrm{mg} \mathrm{kg}^{-1}$ day $^{-1}$ ) and E. caucasicum (100 mg kg-1 day ${ }^{-1}$ ) significantly increased their survival rate compared to untreated infected control $(\mathrm{P}<0.05)$.

Conclusion: These extracts are promising candidates for further medicine development on toxoplasmosis. However, further investigations are necessary to clarify effective fractions of the Z. mays and E. caucasicum extracts and the mechanisms of action.

\section{Introduction}

Toxoplasmosis is a worldwide health problem that caused by intracellular apicomplexan parasite, Toxoplasma gondii (T. gondii) [1]. It is estimated that more than 1 billion people are infected with T. gondii [2]. T.
(@) This is an Open-Access article distributed under the terms of the Creative Commons Attribution Non-Commercial License (http://creativecommons.org/licenses/by-nc/4.0/) which permits unrestricted noncommercial use, distribution, and reproduction in any medium, provided the original work is properly cited.

$\otimes$ This paper meets the requirements of KS X ISO 9706, ISO 9706-1994 and ANSI/NISO Z39.48-1992 (Permanence of Paper).
Corresponding Autho

Ahmad Daryani. Department of Parasitology and Mycology, Sari Medical School, Mazandaran University of Medical Sciences, PC 48168-95475, Sari, Iran. Tel: +98-11-3324-1031 Fax: +98-11-3354-3249

E-mail: daryanii@yahoo.com

(c) 2019 Korean Pharmacopuncture Institute

http://www.journal.ac 
gondii prevalence in some countries is high (e.g. Brazil, 77.5\%; Sao Tome and Principe, 75.2\%; Iran, 63.9\%; Colombia, 63.5\%; and Cuba, 61.8\%) [3]. Globally, the annual incidence of congenital toxoplasmosis is estimated to be 190,100 cases [4].

Although acute toxoplasmosis in healthy individuals is usually asymptomatic, it can lead to great mortality rates in immunocompromised hosts or congenitally infected infants $[5,6]$.

Currently, the first-line therapy for treatment or prophylaxis of toxoplasmosis is the combination of pyrimethamine and sulfadiazine in the clinic [7]. Unfortunately, these drugs have serious side effects. Pyrimethamine can lead to suppression of bone marrow and hematological toxicity [8]. In addition, azithromycin, clarithromycin, spiramycin, atovaquone, dapsone, and cotrimoxazole (trimethoprim-sulfamethoxazole), have been used for clinical toxoplasmosis. However, these drugs are poorly tolerated and have no effect on the bradyzoite form of the parasite [9-11].

Like other apicomplexa such as Plasmodium spp. resistance to anti-Toxoplasma drugs has also been reported in T. gondii [12]. Despite great progress in pharmacological and immunological researches, there is no available drug for treatment of chronic toxoplasmosis. In addition, there is no effective vaccine for prevention of infection in human $[8,13,14]$. Accordingly, new drugs with lack of toxicity and teratogenicity, effective penetration in the placenta, and parasiticidal effect against the different stage of Toxoplasma particularly cystic form are critically needed [15]. There are increasing studies of therapeutic potential of natural or herbal products and medicinal plants are considered to be generally safe and have low toxicity compared to synthetic drugs [16]. Natural products are the source of most drugs in clinical use. Plants have been used as a base or precursors to the development of new synthetic or semi-synthetic drugs with anti-infectious activity, such as antiprotozoal and antibacterial $[16,17]$, or immunomodulatory activity [18]. Based on studies, approximately $70 \%$ of new anti-infective drugs are of natural origin, including 14 approved antiparasitics [19]. Natural products provide a unique structural variety, and a valuable opportunity for the discovery of new active compounds of low molecular weight [20].

Considering the aforementioned side effects of drugs against toxoplasmosis, currently multitude efforts are concentrated on the use of plant extracts to improve the therapies and many researchers have focused on therapeutic potential of natural products against T. gondii [21]. According to our previous study, the extracts of Feijoa sellowiana (leaves and fruits), Quercus castaneifolia (fruits), and Allium paradoxum (leaves) were evaluated against T. gondii [22]. Currently no natural products exist that have been patented for use in the treatment of toxoplasmosis [20].

Zea mays (Z. mays), a traditional medicine, was used for the treatment of interstitial cystitis, diuretic, edema, kidney stones, prostate disorder, and urinary infections in many parts of the world [23]. Also, Eryngium caucasicum (E. caucasicum) is a new cultivated vegetable plant in northern Iran and the antioxidant activity of leaves and inflorescence has recently been shown [24, 25]. No data are available on the effects of these valuable herbs on $\mathrm{T}$. gondii and other parasitic infections. Therefore, the current study was performed to evaluate the in vitro and in vivo effects of methanolic extract from Z. mays and E. caucasicum against $\mathrm{RH}$ strain of $\mathrm{T}$. gondii.

\section{Material and Methods}

\subsection{Plant material}

Dried cut stigmata of Z. mays L, Poaceae flowers, used for this investigation. Plant specimen was collected from Mazandaran province, Iran, in January 2015 and authenticated by Dr. Bahman Eslami (Department of Biology, Islamic Azad University of Qhaemshahr, Iran) and the voucher specimen was deposited in the Sari School of Pharmacy herbarium (No. HS280). E. caucasicum leaf was collected from khazar abad area, Mazandaran province, Iran, and identified by Dr. Bahman Eslami. A voucher (No. 987) has been deposited in the Sari School of Pharmacy herbarium. The plants dried under shade, and powdered mechanically using a commercial electrical blender in the Sari School of Pharmacy.

\subsection{Extracts preparation}

To obtain the Z. mays and E. caucasicum methanolic extracts, $150 \mathrm{~g}$ of dry powder was added to $350 \mathrm{~mL}$ of pure methanol and mixed gradually for 1 hour using a magnetic stirrer. The solution was left at room temperature overnight and filtered through Whatman No. 1 filter paper after sterilization. Then the solvent was removed at $40{ }^{\circ} \mathrm{C}$ with a rotary evaporator. The remaining semi solid material was freeze-dried at $-50{ }^{\circ} \mathrm{C}$ for $24 \mathrm{~h}$. The final crude extracts $(14.5$ g) was placed into a sterile glass container and kept at $4{ }^{\circ} \mathrm{C}$ for further use [26].

\subsection{T. gondii strain}

Tachyzoites of T. gondii virulent RH strain was maintained in Swiss Webster mice. Parasites were propagated intraperitoneal (i.p.) every 3-4 days. The tachyzoites were purified in sterile Phosphate-Buffered Saline (PBS) containing penicillin and streptomycin, $100 \mathrm{IU} \mathrm{mL}^{-1}$ and $100 \mathrm{mg} \mathrm{mL}^{-1}$, respectively [22]. Number of tachyzoites was determined by counting in a hemocytometer under light microscopy.

\subsection{Mice}

Female inbred Balb/c mice weighing 18-20 g (six-week old) were used for the present study. This research underwent ethical review and was approved by the Research Ethics Committee of Mazandaran University of Medical Sciences. Care and use of laboratory animals complied with local animal welfare laws, policies, and guidelines. All experimental mice were housed in cages $(n=5)$ under standard laboratory conditions (with an average temperature $20-25{ }^{\circ} \mathrm{C}$, given drinking water and regular mouse diet) [27].

\subsection{Anti-Toxoplasma activity of the extracts in vitro}


Four concentrations $\left(5,10,25\right.$, and $\left.50 \mathrm{mg} / \mathrm{mL}^{-1}\right)$ of the Z. mays and E. caucasicum extracts were accessed for 30 , 60,120 and $180 \mathrm{~min}$. Two $\mathrm{mL}$ of each concentration and $4 \times 106$ fresh T. gondii tachyzoites were put into a test tube. The contents of the tubes were mixed gently and incubated at $37{ }^{\circ} \mathrm{C}$ for $30,60,120$ and $180 \mathrm{~min}$. After the end of each incubation time, two $\mathrm{mL}$ of $0.5 \%$ (w/v) trypan blue dye was added to the settled tachyzoites. The remained pellet of tachyzoites was smeared on a glass slide. The percentage of dead tachyzoites was determined by counting 200 tachyzoites under a light microscope. Tubes containing pyrimethamine in concentration of $100 \mathrm{mg} \mathrm{mL}^{-1}$ and PBS were considered as positive and negative control groups, respectively. All experiments were performed in triplicate in this study.

\subsection{Anti-Toxoplasma activity of the extracts in vivo}

For assaying of anti-Toxoplasma activity in vivo, 30 female Balb/c mice were infected i.p. with $2 \times 104$ tachyzoites of T. gondii RH strain and distributed into six groups, each with 5 mice, that were treated on the same day of inoculum, during 5 days i.p. at regular 24-h intervals as follows: Z. mays, E. caucasicum (100 and $200 \mathrm{mg} / \mathrm{kg}^{-1} /$ day $\left.^{-1}\right)$, pyrimethamine (50 mg / $\mathrm{kg}^{-1} /$ day $^{-1}$ ) (positive control) and PBS (negative control). The mice were monitored daily for mortality and the morbidity. The survival periods were recorded daily until all mice died. Initially, for controlling of drug side effects, a preliminary experiment was done on $\mathrm{Balb} / \mathrm{c}$ mice receiving the same dose of drugs and no mortality or clinically significant toxicity was observed.

\subsection{Statistical analysis}

Statistical analysis was performed with SPSS-14. Differences between the test and control groups were analyzed using repeated measures ANOVA test. Also, the KaplanMeier curve was used to show the survival time and by using log-rank test, the survival rates among different groups were compared. Differences were considered statistically significant when $\mathrm{P}<0.05$.

\section{Results}

\subsection{Effects of the extracts on $\mathrm{T}$. gondii in vitro}

Based on in vitro results, the extract of $\mathrm{Z}$. mays at the concentration of $5 \mathrm{mg}$ mL-1 killed $97.08 \%$ of tachyzoites after $180 \mathrm{~min}$. Also, Z. mays (10, 25 and $\left.50 \mathrm{mg} / \mathrm{mL}^{-1}\right)$ after 120 and $180 \mathrm{~min}$ killed $100 \%$ of the parasites. It is notable that

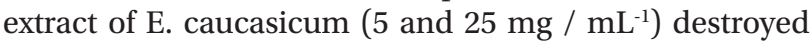
$91.58 \%$ and $96.29 \%$ of the parasites after $180 \mathrm{~min}$, respectively. The anti-Toxoplasma effect of the methanolic extracts were statistically significant compared to the negative control group in all exposure times $(\mathrm{P}<0.05)$. Furthermore, pyrimethamine $\left(50 \mathrm{mg} / \mathrm{mL}^{-1}\right)$ after $180 \mathrm{~min}$ destroyed $98.64 \%$ of the tachyzoites. The anti-Toxoplasma effects of the Z. mays and E. caucasicum extracts are summarized in Table 1, 2.

\subsection{Effects of the extracts on T. gondii in vivo}

Clinically, the numbers of mice in untreated infected groups (negative control) started to reduce on the seventh day of study and all mice died before the eighth day. Mice

Table 1 Anti- Toxoplasma activity of Zea mays extract in vitro.

\begin{tabular}{|c|c|c|c|c|c|c|}
\hline \multirow[t]{2}{*}{ Groups } & \multirow{2}{*}{$\begin{array}{c}\text { Concentration } \\
(\mathrm{mg} / \mathrm{mL})\end{array}$} & \multicolumn{4}{|c|}{ Time } & \multirow[t]{2}{*}{ P-value } \\
\hline & & $30 \mathrm{~min}$ & $60 \mathrm{~min}$ & $120 \mathrm{~min}$ & $180 \mathrm{~min}$ & \\
\hline \multirow{4}{*}{ Case } & 5 & $56.73 \pm 5.26$ & $70.40 \pm 8.59$ & $96.46 \pm 1.39$ & $97.08 \pm 2.19$ & $0.003 *$ \\
\hline & 10 & $82.02 \pm 0.21$ & $85.56 \pm 2.74$ & $97.61 \pm 1.21$ & $100 \pm 0.00$ & $<0.01 *$ \\
\hline & 25 & $86.78 \pm 2.48$ & $90.26 \pm 3.16$ & $98.28 \pm 1.33$ & $100 \pm 0.00$ & $<0.01 *$ \\
\hline & 50 & $90.54 \pm 5.14$ & $95.17 \pm 1.97$ & $100 \pm 0.00$ & $100 \pm 0.00$ & $>0.05$ \\
\hline Pos control & 100 & $15.59 \pm 1.96$ & $69.37 \pm 8.36$ & $95.46 \pm 0.48$ & $98.64 \pm 1.92$ & $0.001 *$ \\
\hline Neg control & - & $3.5 \pm 0.14$ & $3.6 \pm 0.07$ & $4 \pm 0.21$ & $4.8 \pm 0.21$ & $>0.05$ \\
\hline
\end{tabular}

Table 2 Table 2 Anti- Toxoplasma activity of Eryngium caucasicum extract in vitro.

\begin{tabular}{lcccccc}
\hline Groups & $\begin{array}{c}\text { Concentration } \\
(\mathrm{mg} / \mathrm{mL})\end{array}$ & \multicolumn{4}{c}{ Time } & P-value \\
\cline { 3 - 6 } & & $30 \mathrm{~min}$ & $60 \mathrm{~min}$ & $120 \mathrm{~min}$ & $180 \mathrm{~min}$ & \\
\hline \multirow{3}{*}{ Case } & 5 & $57.51 \pm 8.88$ & $73.37 \pm 0.12$ & $85.36 \pm 1.57$ & $91.58 \pm 1.75$ & $<0.05^{*}$ \\
& 10 & $66.88 \pm 11.23$ & $80.87 \pm 1.81$ & $87.79 \pm 2.69$ & $94.16 \pm 0.33$ & $<0.05^{*}$ \\
& 25 & $67.15 \pm 3.71$ & $87.45 \pm 0.91$ & $90.12 \pm 1.01$ & $96.29 \pm 1.50$ & $0.007^{*}$ \\
Pos control & 50 & $80.42 \pm 10.10$ & $94.44 \pm 3.93$ & $94.20 \pm 0.16$ & $94.91 \pm 2.96$ & $>0.05$ \\
Neg control & 100 & $15.59 \pm 1.96$ & $69.37 \pm 8.36$ & $95.46 \pm 0.48$ & $98.64 \pm 1.92$ & $0.001^{*}$ \\
\hline
\end{tabular}

Pos control: Positive control group receiving $100 \mathrm{mg} \mathrm{mL}^{-1}$ pyrimethamine, Neg control:

Negative control group receiving PBS, * Statistically significant compared to control group. 
of Z. mays, E. caucasicum and pyrimethamine groups started to die on the seventh day until the eleventh day. The treatment with $\mathrm{Z}$. mays and E. caucasicum (100 mg $/ \mathrm{kg}^{-1} /$ day $^{-1}$ ) lead to better results in mice survival than treatment with Z. mays and E. caucasicum (200 mg / kg-1 / day $^{-1}$ ) (Fig. 1).

Mice in the treatment groups of Z. mays (100 and 200 mg kg-1 day-1) and E. caucasicum (100 mg / kg-1 / day $\left.{ }^{-1}\right)$ showed statistically higher survival rate compared to untreated infected control $(\mathrm{P}<0.05)$. There was significant difference between Z. mays (100 and $200 \mathrm{mg} / \mathrm{kg}^{-1} /$ day $^{-1}$ ) and E. caucasicum (200 mg / $\mathrm{kg}^{-1} /$ day $\left.^{-1}\right)$ groups with the positive control $(\mathrm{P}<0.05)$.

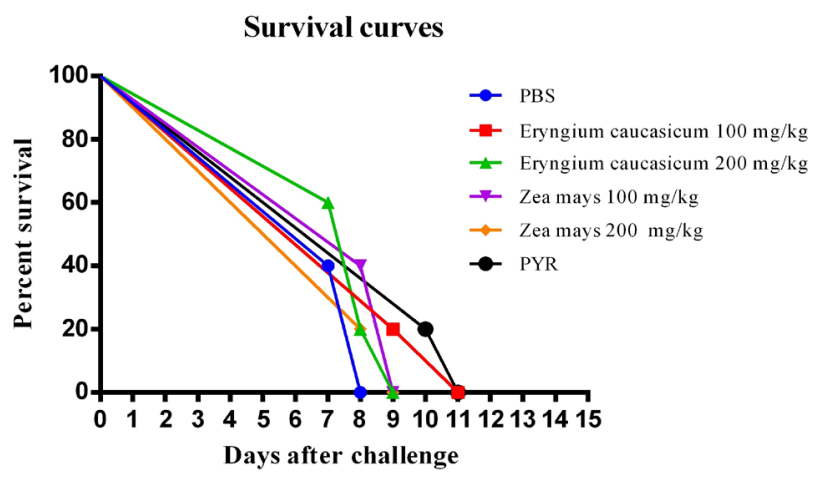

Figure 1 The survival curves of mice following acute toxoplasmosis. BALB/c mice ( $\mathrm{n}=5)$ infected with $2 \times 104$ tachyzoites of the T. gondii $\mathrm{RH}$ strain were treated with the $\mathrm{Z}$. mays and E. caucasicum extract 100, $200 \mathrm{mg} / \mathrm{kg}^{-1} /$ day $^{-1}$, pyrimethamine (50 mg $/ \mathrm{kg}^{-1} /$ day $^{-1}$ ) (as the positive control) and PBS (as the negative control) for 5 days via the intraperitoneal route.

\section{Discussion}

In the present study, we evaluated the efficacies of $\mathrm{Z}$. mays and E. caucasicum on T. gondii infection in vitro and in vivo for the first time. In the in vitro tests, the anti-Toxoplasma effect of the methanolic extracts were statistically significant compared to the negative control group in all exposure times $(\mathrm{P}<0.05)$, and they did not show any significant difference compared to pyrimethamine (positive control). Interestingly, the Z. mays (10, 25 and $50 \mathrm{mg} / \mathrm{mL}^{-1}$ ) after 180 and 120 min killed $100 \%$ of the tachyzoites, respectively. Also, the E. caucasicum (25 mg / $\left.\mathrm{mL}^{-1}\right)$ after 180 min killed $96.29 \%$ of the tachyzoites indicating that both $\mathrm{Z}$. mays and E. caucasicum had been shown high toxoplasmacidal activity.

Actually, the current anti- T. gondii chemotherapy is deficient [8]. Natural compounds and traditional herbal medicine may be developed as a source of valuable pharmacologically active agents that improve the treatment of toxoplasmosis. These novel therapeutic agents have high availability and lower side effects, compared with the current chemical drugs [22]. There are many herbal compounds against fungi, protozoa and helminthes, and some have anti- T. gondii properties such as Curcuma longa [28], Eurycoma longifolia Jack [29, 30], and Myristica fragrans Houtt [31], etc. However, Z. mays and E. caucasicum extracts have not been examined for their potential anti- Toxoplasma properties. Herbal extract of Z. mays, as traditional medicine, was used for the treatment of cystitis, kidney stones, edema, diuretic, and urinary infections in many parts of the world [23]. Also, E. caucasicum is a new cultivated vegetable plant in northern Iran and the antioxidant activity of leaves and inflorescence has recently been shown [24, 25].

Previously we have shown that the fruits and leaves of Sambucus nigra at the concentrations of 5, 10 and $25 \mathrm{mg}$ / $\mathrm{mL}$ after $180 \mathrm{~min}$, and concentration of $50 \mathrm{mg} / \mathrm{mL}$ after $60 \mathrm{~min}$, resulted with the highest efficacy [26].Also, Leesombun et al. reported that $25 \mu \mathrm{g} / \mathrm{mL}-1$ of the Piper betle extract eradicated T. gondii in vitro [32]. Similarly, our data indicated that extract of Z. mays and E. caucasicum had high toxoplasmacidal activity in vitro.

Considering the in vitro anti-T. gondii activity of $\mathrm{Z}$. mays and E. caucasicum extracts, we evaluated the effects of these extracts in acute T. gondii infection model with virulent RH strain in Balb/c mice. Treatment of experimental mice with the Z. mays (100, $200 \mathrm{mg} \mathrm{kg}^{-1}$ day $\left.^{-1}\right)$ and $\mathrm{E}$. caucasicum ( $100 \mathrm{mg} / \mathrm{kg}^{-1} /$ day $\left.^{-1}\right)$ for 5 days after infection with $2 \times 104$ tachyzoites of the T. gondii RH strain increased statistically their survival rate than untreated infected control statistically $(\mathrm{P}<0.05)$. Moreover, the mice treated with E. caucasicum (100 mg / $\mathrm{kg}^{-1} / \mathrm{day}^{-1}$ ) also achieved better effect in survival compared with other groups. Similarly, Zhang et al. have shown that oxymatrine and matrine, two Sophora alkaloids, have unique properties against T. gondii tachyzoites in vitro and in vivo [33].

In our study, Z. mays and E. caucasicum were more effective at doses $\left(100 \mathrm{mg} \mathrm{kg}^{-1}\right.$ day $\left.^{-1}\right)$ in the acute phase of infection. However, the anti-toxoplasmic mechanism of the extracts is not known. Similar effects were reported for endochin-like quinolone: ELQ-271 and ELQ-316 at low doses were highly active against $\mathrm{T}$. gondii in mice [34]. Leesombun et al. performed a mouse survival study and reported that Piper betle extract was highly effective against T. gondii in vivo [32]. Accordingly, E. caucasicum extract (100 mg $/ \mathrm{kg}^{-1} /$ day $^{-1}$ ) was effective as pyrimethamine for control of infection. However, there is no difference between E. caucasicum and pyrimethamine.

Previously we have shown that the propranolol and ketotifen combined with pyrimethamine was more effective in inhibiting growth of tachyzoites when compared with propranolol and pyrimethamine alone on murine toxoplasmosis [35, 36, 37]. Therefore, further studies should be performed to compare the efficacy of Z. mays and E. caucasicum combination in inhibiting growth of $\mathrm{T}$. gondii.

\section{Conclusion}

The present results clearly indicated that the methanolic extracts have promising efficacies on tachyzoites of $\mathrm{T}$. gondii in vitro. Also these extracts were effective for acute toxoplasmosis of RH strain of T. gondii in vivo more investigations are required to determine active compounds of Z. mays and E. caucasicum in which act as anti-Toxoplasma agents. However, further study should be conducted to investigate potential bioactives of these extracts through bioactivity guided fractionation. 


\section{Conflict of interest}

There is no conflict of interests.

\section{Acknowledgment}

We acknowledge the financial support of grant (No. 9268) from the Mazandaran University of Medical Science, Iran. Authors would like to thank Student Research Committee, Mazandaran University of Medical Sciences, Sari, Iran.

\section{References}

1. Montoya JG, Liesenfeld O. Toxoplasmosis. Lancet. 2004;12;363(9425):1965-76.

2. Hoffmann S, Batz MB, Morris Jr JG. Annual cost of illness and quality-adjusted life year losses in the United States due to 14 foodborne pathogens. J Food Prot. 2012;75(7):1292-302.

3. Pappas G, Roussos N, Falagas ME. Toxoplasmosis snapshots: global status of Toxoplasma gondii seroprevalence and implications for pregnancy and congenital toxoplasmosis. Int J Parasitol. 2009;39(12):1385-94.

4. Torgerson PR, Mastroiacovo P. The global burden of congenital toxoplasmosis: a systematic review. Bull World Health Organ. 2013;91(7):501-8.

5. Dubey J, Jones J. Toxoplasma gondii infection in humans and animals in the United States. Int J Parasitol. 2008;38(11):1257-78.

6. Ahmadpour E, Daryani A, Sharif M, Sarvi S, Aarabi M, Mizani A, et al. Toxoplasmosis in immunocompromised patients in Iran: a systematic review and meta-analysis. J Infect Dev Ctries. 2014;8(12):1503-10.

7. Montoya J, Liesenfeld O. Toxoplasmosis. The Lancet. 2004;363(9425):1965-76.

8. Rodriguez JB, Szajnman SH. New antibacterials for the treatment of toxoplasmosis; a patent review. Expert Opin Ther Pat. 2012;22(3):311-33.

9. Araujo FG, Remington JS. Recent advances in the search for new drugs for treatment of toxoplasmosis. Int J Antimicrob Agents. 1992;1(4):153-64.

10. Petersen E, Schmidt DR. Sulfadiazine and pyrimethamine in the postnatal treatment of congenital toxoplasmosis: what are the options? Expert Rev Anti Infect Ther. 2003;1(1):175-82.

11. Serranti D, Buonsenso D, Valentini P. Congenital toxoplasmosis treatment. Eur Rev Med Pharmacol Sci. 2011;15(2):193-8.

12. Aspinall TV, Joynson DH, Guy E, Hyde JE, Sims PF. The molecular basis of sulfonamide resistance in Toxoplasma gondii and implications for the clinical management of toxoplasmosis. J Infect Dis. 2002;185(11):1637-43.

13. Ahmadpour E, Sarvi S, Hashemi Soteh MB, Sharif M, Rahimi MT, Valadan R, et al. Enhancing immune responses to a DNA vaccine encoding Toxoplasma gondii GRA14 by Calcium Phosphate nanoparticles as an adjuvant. Immunol Lett. 2017;185:40-47.

14. Ahmadpour E, Sarvi S, Hashemi Soteh MB, Sharif M, Rahimi MT, Valadan R, et al. Evaluation of the immune response in $\mathrm{BALB} / \mathrm{c}$ mice induced by a novel DNA vaccine expressing GRA14 against Toxoplasma gondii. Parasite Immunol. 2017;39(4).

15. Montazeri M, Sharif M, Sarvi S, Mehrzadi S, Ahmadpour E, Daryani A. A Systematic Review of In Vitro and In Vivo Activities of Anti-Toxoplasma Drugs and Compounds (2006 to 2016). Front Microbiol. 2017;8:25.

16. Newman DJ, Cragg GM. Natural products as sources of new drugs from 1981 to 2014. J Nat Prod. 2016;79(3):629-61.

17. Sharif M, Ziaei H, Azadbakht M, Daryani A, Ebadattalab A, Rostami M. Effect of methanolic extracts of Artemisia aucheri and Camellia sinensis on Leishmania major (in vitro). Turk J Med Sci. 2007;36(6):365-9.

18. Kayser O, Masihi KN, Kiderlen AF. Natural products 
and synthetic compounds as immunomodulators. Expert Rev Anti Infect Ther. 2003;1(2):319-35.

19. Newman DJ, Cragg GM. Natural products as sources of new drugs over the 30 years from 1981 to 2010. Nat Prod J. 2012;75(3):311-35.

20. C Sepulveda-Arias J, A Veloza L, E Mantilla-Muriel L. Anti-Toxoplasma activity of natural products: a review. Recent Pat Antiinfect Drug Discov. 2014;9(3):186-94.

21. Choi K-M, Gang J, Yun J. Anti-Toxoplasma gondii RH strain activity of herbal extracts used in traditional medicine. Int J Antimicrob Agents. 2008;32(4):360-2.

22. Ebrahimzadeh MA, Mohammad Taheri M, Ahmadpour E, Montazeri M, Sarvi S, Akbari M, et al. Anti-Toxoplasma effects of Methanol Extracts of Feijoa sellowiana, Quercus castaneifolia, and Allium paradoxum. J Pharmacopuncture. 2017;20(2):107-11

23. Hasanudin K, Hashim P, Mustafa S. Corn silk (Stigma maydis) in healthcare: a phytochemical and pharmacological review. Molecules. 2012;17(8):9697-715.

24. Nabavi S, Nabavi S, Alinezhad H, Zare M, Azimi R. Biological activities of flavonoid- rich fraction of Eryngium caucasicum Trautv. Eur Rev Med Pharmacol Sci. 2012;16:81-7.

25. Ebrahimzadeh MA, Nabavi SF, Nabavi SM. Antioxidant activity of leaves and inflorescence of Eryngium caucasicum Trautv at flowering stage. PharmacognosyRes. 2009;1(6):435.

26. Daryani A, Ebrahimzadeh MA, Sharif M, Ahmadpour E, Edalatian S, Esboei BR, et al. Anti-Toxoplasma activities of methanolic extract of Sambucus nigra (Caprifoliaceae) fruits and leaves. Rev biol trop. 2015;63(1):07-12.

27. Akins CK, Panicker SE, Cunningham CL. Laboratory animals in research and teaching: Ethics, care, and methods: American Psychological Association; 2005.

28. Al-Zanbagi NA. In vivo effect of some home spices extracts on the Toxoplasma gondii tachyzoites. J Family Community Med. 2009;16(2):59.

29. Khanam Z, Wen CS, Bhat IUH. Phytochemical screening and antimicrobial activity of root and stem extracts of wild Eurycoma longifolia Jack (Tongkat Ali). JKSUS. 2015;27(1):23- 30.

30. Kavitha N, Noordin R, Chan K-L, Sasidharan S. In vitro anti-Toxoplasma gondii activity of root extract/fractions of Eurycoma longifolia Jack. BMC complementary and alternative medicine. 2012;12(1):1.

31. Pillai S, Mahmud R, Lee WC, Perumal S. Anti-parasitic activity of Myristica fragrans Houtt. essential oil against Toxoplasma gondii parasite. APCBEE Procedia. 2012;2:92-6.

32. Leesombun A, Boonmasawai S, Shimoda N, Nishikawa Y. Effects of Extracts from Thai Piperaceae Plants against Infection with Toxoplasma gondii. PloS one. 2016;11(5):e0156116.

33. Zhang X, Jin L, Cui Z, Zhang C, Wu X, Park H, et al. Antiparasitic effects of oxymatrine and matrine against Toxoplasma gondii in vitro and in vivo. Exp Parasitol. 2016;165:95-102.

34. Doggett JS, Nilsen A, Forquer I, Wegmann KW, Jones-Brando L, Yolken RH, et al. Endochin-like quinolones are highly efficacious against acute and latent experimental toxoplasmosis. Proc Natl Acad Sci.
2012;109(39):15936-41.

35. Montazeri M, Daryani A, Ebrahimzadeh M, Ahmadpour E, Sharif M, Sarvi S. Effect of propranolol alone and in combination with pyrimethamine on acute murine toxoplasmosis. Jundishapur J Microbiol. 2015;8(9).

36. Montazeri M, Ebrahimzadeh MA, Ahmadpour E, Sharif M, Sarvi S, Daryani A. Evaluation of Propranolol Effect on Experimental Acute and Chronic Toxoplasmosis using Q- PCR. Antimicrob Agents Chemother. 2016;60(12):7128-33.

37. Montazeri, M, Rezaei, K, Ebrahimzadeh, MA, Sharif, M, Sarvi, S, Ahmadpour, E, et al. Survey on synergism effect of ketotifen in combination with pyrimethamine in treatment of acute murine toxoplasmosis. Trop Med Int. 2017;45(1):39. 